\title{
Modelling of Power Consumption in Two Base Stations, Using Ugbor Station and Benson Idahosa University Station in Benin City as a Case Study
}

\author{
Ihedi-Okonkwo Nick Obinna \\ Department of Computer Engineering, \\ University of Benin, Benin City, \\ Edo State, Nigeria.
}

\begin{abstract}
This research is on the analysis and modelling of power consumption in a base transceiver station. For the purpose of this research, two base transceiver stations in Benin (BEN) were visited and data were collected and analysed: Ugbor station referred to as BEN035 (site A) and Benson Idahosa University referred to as BEN198 (site B). Analysis was made on AC power consumption and its Matlab plot. The model of Base station instantaneous DC power consumption for high and low traffic global system of mobile communication (GSM) usage was carried out by Matlab software to show how power is been consumed in a Base transceiver Station (BTS) and for future forecast.
\end{abstract}

Keywords:- Base transceiver station, modelling, power consumption, Forecast, Matlab software and telecommunication.

\section{INTRODUCTION}

This covers the power consumption of the equipment that make up the base transceiver station, the modelling of the BTS from the data collected from the two base stations. It also shows the plot of the alternating current (AC) power

\author{
Omosigho Emmanuel Osawaru \\ Department of Electrical Engineering Technology, \\ National Institute of Construction Technology and \\ Management, Uromi Edo State, Nigeria.
}

consumption consisting of the three phases and direct current (DC) instantaneous power consumption in the sectors of the base station technology. Base stations equipment is likely to consume more power depending on its usage. Being able to forecast the power consumption at a stipulated period of time will provide a measure and techniques to reduce the power consumption at an early stage and hence save cost and optimize profit for the operators.

\section{THEORETICAL POWER CONSUMPTION OF BASE TRANSCEIVER STATION (BTS)}

Base Transceiver Station (BTS) - is a transceiver and acts as interface between the mobile stations (MS) to the network. A BTS will have between 1 and 16 Transceivers (TRX), depending on the geography and demand for service of an area. Each TRX represents one Absolute radio frequency channel number (ARFCN). However, depending on geography, service demand and operator's network strategy and architecture, a BTS may be host up to two, three or six sectors, or a cell may be serviced by several BTSs with redundant sector coverage. Each sector is covered by sector antenna, which is a directional antenna.

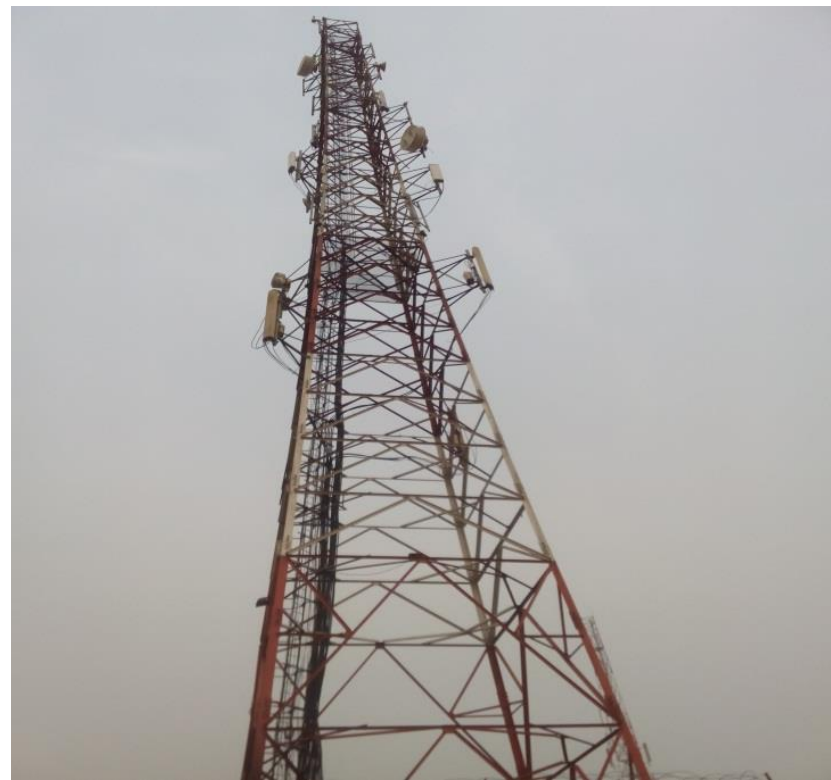

Fig 1:- Typical macro base station 
In Figure 1, there are several power consuming equipment. Some equipment are used per sector such as the digital signal processing (DSP) which is responsible for system processing and coding, the power amplifier, the transceiver which is responsible for generating the signal and also receiving signals to the mobile station and the rectifier as shown in Figure 2.The power consumption of such equipment should be multiplied by the number of sectors when determining the power consumption of BTSs. Within these equipment the transceiver and the power amplifier are one per transmitting antenna. Other equipment such as the air conditioning and the microwave link, when no fiber link is available for backhaul, are common to all sectors.

Power consumption for each of the equipment is always the same except for the power amplifier and the air conditional system. For amplifier, the power consumption solely depends on the efficiency of the amplifier.

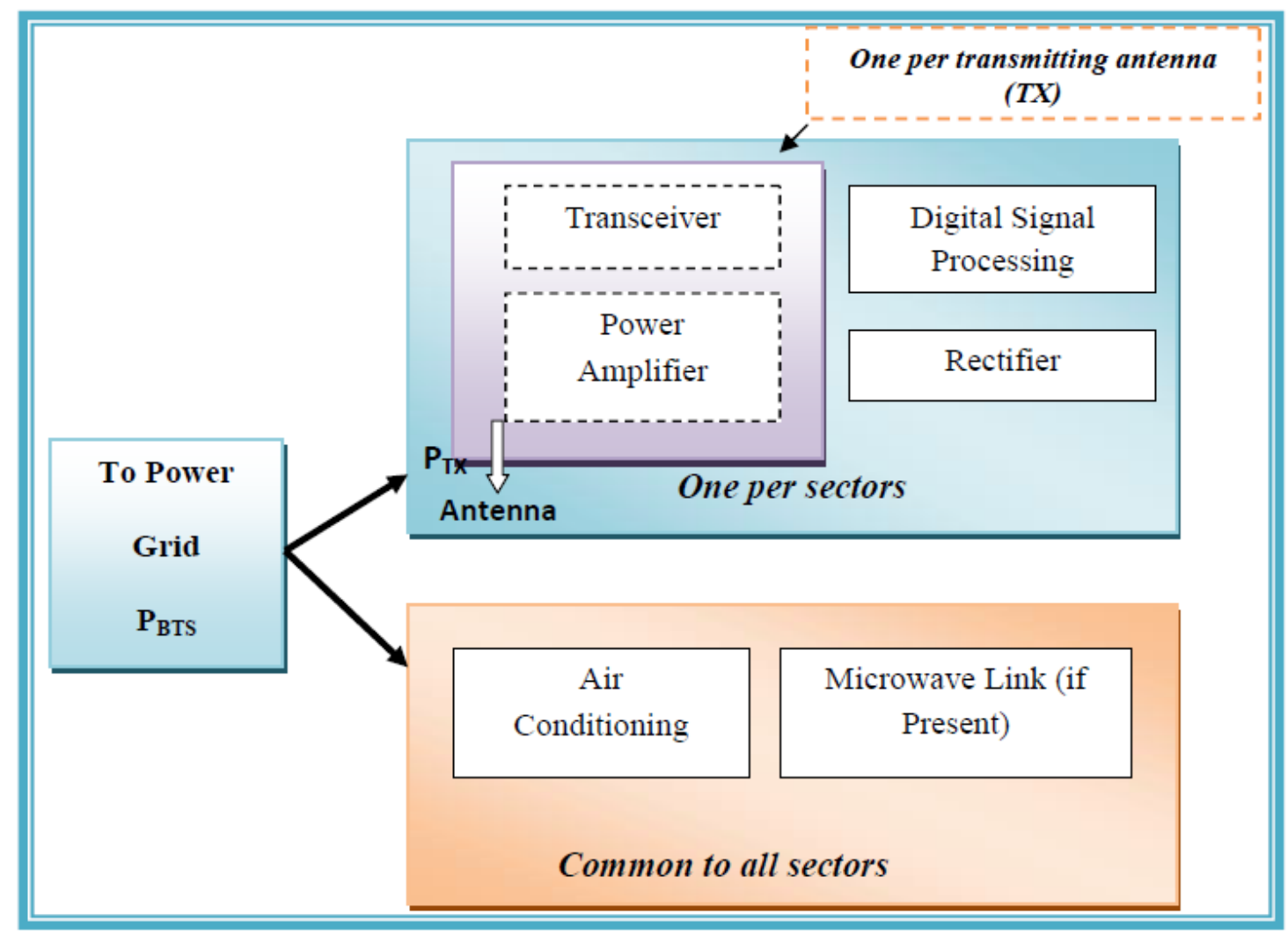

Fig 2:- Block Diagram of Base Station Equipment.

In the case of the air conditioning system (AC), the power consumption varies with the internal and ambient temperature of the BTS cabinet. Considering the ambient temperature to be $25^{\circ} \mathrm{C}$, this is not always the case in Nigeria. The internal and ambient temperature varies with locations.

Therefore, when estimating power consumption of air conditioning system, the worst case temperature scenario is considered.

In theoretical based power consumption, analytic model is developed to estimates the power consumption of a base station. Though in some cases, the estimation never gives the realistic power consumption but somehow approximations. This indicates that once the power consumption of individual equipment of the base station is known, the total power consumption could be evaluated

\section{A. Load Demand in a Base Transceiver Station}

In this work, two base station is been considered, which are BEN035 (Base station A) and BEN198 (Base station B) in Benin City, Edo State, Nigeria. Base station A has many links, services more geographical area (more subscribers) and in turn consumes more power than the base station B which serves less geographical area (less subscribers).

A Base transceiver station that is operating in Nigeria (BEN035) has the load demand in the table 1. It consists of $3 \mathrm{G}$ network access cabinet. 
ISSN No:-2456-2165

\begin{tabular}{|c|c|c|c|c|c|c|}
\hline $\mathbf{S} / \mathbf{N}$ & Equipment & $\begin{array}{l}\text { Model } \\
\text { (Type) }\end{array}$ & Quantity & $\begin{array}{l}\text { Power Rating } \\
\text { (Watts) }\end{array}$ & $\begin{array}{c}\text { No of } \\
\text { Hours } \\
\text { Used }\end{array}$ & $\begin{array}{l}\text { Daily Hour Used } \\
\text { (kwh) }\end{array}$ \\
\hline 1. & Transceiver(3G) (DC) & Huawei & 4 & 3200 & 24 & 76.8 \\
\hline 2. & Base band unit (DC) & Huawei & 1 & 180 & 24 & 4.32 \\
\hline 3. & Air conditioner (AC) & Chigo & 2 & 1700 & 24 & 40.8 \\
\hline 4. & Indoor light (AC) & Philips & 2 & 64 & 12 & 0.768 \\
\hline 5. & Security light (AC) & Tostar & 1 & 32 & 12 & 0.384 \\
\hline 6. & Rectifier (AC) & Delta & 1 & 2400 & 24 & 57.6 \\
\hline 7. & Microwave antenna (DC) & Ericsson & 5 & 25 & 24 & 0.6 \\
\hline 8. & GSM Antenna (DC) & Acatel & 3 & 60 & 24 & 1.44 \\
\hline 9. & Multiplexer (DC) & Acatel & 1 & 240 & 24 & 5.76 \\
\hline 10. & $\begin{array}{l}\text { Intermediate frequency links } \\
\text { (DC) }\end{array}$ & Ceragon & 9 & 180 & 24 & 4.32 \\
\hline \multirow[t]{2}{*}{11.} & Router (DC) & Ericsson & 1 & 330 & 24 & 7.92 \\
\hline & \multicolumn{3}{|c|}{ Total energy consumption } & 8,411 & 240 & 200.712 \\
\hline
\end{tabular}

Table 1:- Equipment of a base transceiver station and power rating per hours used in BEN035 (3G)

A Base transceiver station that is operating in Nigeria (BEN198) has the load demand in the table 2. It consists of 3G network access cabinets.

\begin{tabular}{|c|c|c|c|c|c|c|}
\hline S/N & Equipment & $\begin{array}{c}\text { Model } \\
(\text { Type })\end{array}$ & Quantity & $\begin{array}{c}\text { Power Rating } \\
\text { (Watts) }\end{array}$ & $\begin{array}{c}\text { No of } \\
\text { Hours } \\
\text { Used }\end{array}$ & $\begin{array}{c}\text { Daily Hour Used } \\
\text { (kwh) }\end{array}$ \\
\hline 1. & Transceiver(3G) (DC) & Huawei & 2 & 2800 & 24 & 67.2 \\
\hline 2. & Base band unit (DC) & Huawei & 1 & 180 & 24 & 4.32 \\
\hline 3. & Air conditioner (AC) & Chigo & 1 & 900 & 24 & 21.6 \\
\hline 4. & Indoor light (AC) & Philips & 2 & 120 & 12 & 1.44 \\
\hline 5. & Security light (AC) & Philips & 1 & 60 & 12 & 0.72 \\
\hline 6. & Rectifier (AC) & Delta & 1 & 2100 & 24 & 50.4 \\
\hline 7. & Microwave antenna(AC) & Ericsson & 3 & 15 & 24 & 0.36 \\
\hline 8. & GSM Antenna (DC) & Ericsson & 3 & 60 & 24 & 1.44 \\
\hline 9. & $\begin{array}{c}\text { Intermediate frequency (IF) } \\
\text { links }\end{array}$ & Ceragon & 7 & 140 & 24 & 3.36 \\
\hline & \multicolumn{2}{|c|}{ Total energy consumption } & & $\mathbf{6 , 3 7 5}$ & $\mathbf{1 9 2}$ & $\mathbf{1 5 0 . 8 4}$ \\
\hline
\end{tabular}

Table 2:- Equipment of a base transceiver station and power rating per hours used in BEN198 (3G)

From the tables 1 and 2 above, Base station A will consume more power than base station B because base station A has so many links, covers more geographical area and consists of other equipment like the Add and drop multiplexer and router. The fact that base station A uses an indoor (shelter) system, its power consumption is higher since the air conditioning system will do more work compared to base station B which uses an outdoor system that operate on natural convection.

\section{MEASUREMENT OF POWER CONSUMPTION}

Alternating current $(\mathrm{AC})$ from the power grid which is connected to the base station site uses a three phase low voltage system $(415 / 240 \mathrm{~V})$ with a proper TN-S grounding scheme. Residual current device characterized with a nominal current of $40 \mathrm{~A}$ and a differential current of $500 \mathrm{~mA}$ is based on a non-direct touch protecting system. For the base station cabinet to function properly, voltage values from direct current (DC) power supply range from $43 \mathrm{~V}$ to $56 \mathrm{~V}$ was used.

$\mathrm{AC}$ and DC power consumption obtained at the entire base station site was taken at two minutes intervals. This was carried out in the period from $17^{\text {th }}$ February starting at 12:00pm until $21^{\text {st }}$ February ending at 12:00pm. 


\section{A. Alternating Current (AC) Power Consumption}

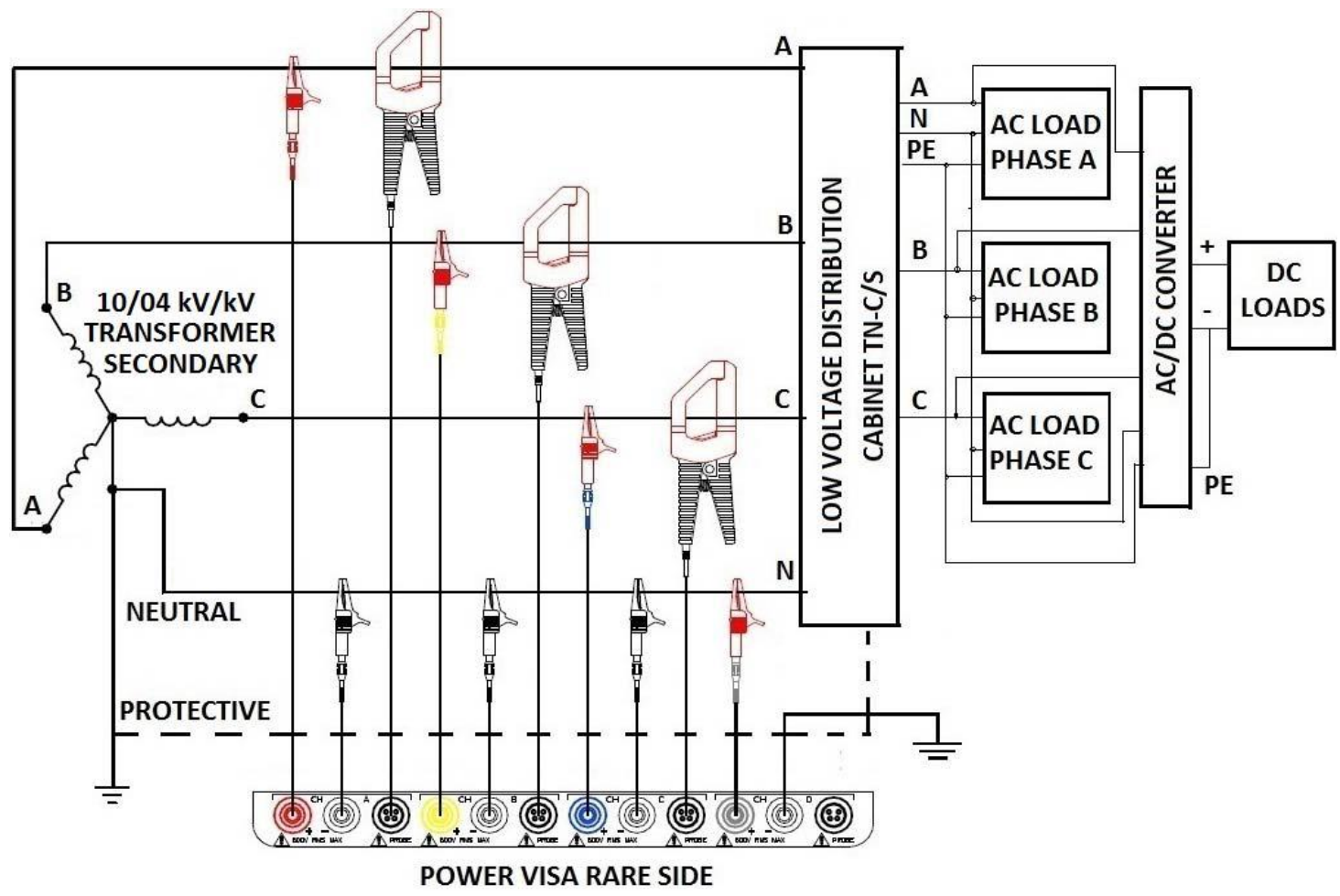

Fig 3:- Contacting scheme for measuring AC consumption of complete BSs site.

Different equipment were used to measure the alternating current energy consumption of the entire site, as well as the air conditioner and the battery supply system. The equipment been used are as follows: laptop with specialized matlab software, flexible Rogowski current- clamps equipped with the embedded signal integrator for currents of up to $3 \mathrm{Ka}$, current clamps for measuring currents up to 30A. UNI-T True Root Mean Square (TRMS) multimeter. The measured signals were concurrently stored to an embedded 2 GB SD memory card and transferred to the laptop via a corresponding adapter.

The measuring scheme according to which measurements of the power consumption on the AC side of the BS site were performed can be seen in Figure 3. As presented in Figure 3, the phase currents were measured using current clamps. The first five values of current from the 2880 values obtained in the period were shown in the tables below.

Table 3 Some of the values obtained from the AC measurement (Phase A) in BEN035 is as follows

\begin{tabular}{|c|c|c|c|c|}
\hline S/N & Current (I) & Voltage (V) & Power (W) & Power (KW) \\
\hline 1. & 23.79 & 240 & 5710 & 5.710 \\
\hline 2. & 23.3 & 240 & 5592 & 5.592 \\
\hline 3. & 23.87 & 240 & 5729 & 5.729 \\
\hline 4. & 23.92 & 240 & 5741 & 5.741 \\
\hline 5. & 24.0 & 240 & 5760 & 5.760 \\
\hline
\end{tabular}

Table 3

Table 4 Some of the values obtained from the AC measurement (Phase B) in BEN035 is as follows

\begin{tabular}{|c|c|c|c|c|}
\hline S/N & Current (I) & Voltage (V) & Power (W) & Power (KW) \\
\hline 1. & 18.17 & 240 & 4361 & 4.361 \\
\hline 2. & 18.94 & 240 & 4546 & 4.546 \\
\hline 3. & 19.41 & 240 & 4658 & 4.658 \\
\hline 4. & 19.10 & 240 & 4584 & 4.584 \\
\hline 5. & 18.40 & 240 & 4416 & 4.416 \\
\hline
\end{tabular}

Table 4 
Table 5 Some of the values obtained from the AC measurement (Phase C) in BEN035 is as follows

\begin{tabular}{|c|c|c|c|c|}
\hline S/N & Current (I) & Voltage (V) & Power (W) & Power (KW) \\
\hline 1. & 18.05 & 240 & 4332 & 4.332 \\
\hline 2. & 18.92 & 240 & 4541 & 4.541 \\
\hline 3. & 19.38 & 240 & 4651 & 4.651 \\
\hline 4. & 19.09 & 240 & 4582 & 4.582 \\
\hline 5. & 18.38 & 240 & 4411 & 4.411 \\
\hline
\end{tabular}

Table 5

Table 6 Some of the values obtained from the AC measurement (Phase A) in BEN198 is as follows

\begin{tabular}{|c|c|c|c|c|}
\hline S/N & Current (I) & Voltage $(\mathrm{V})$ & Power $(\mathrm{W})$ & Power $(\mathrm{KW})$ \\
\hline 1. & 23.79 & 240 & 5710 & 5.710 \\
\hline 2. & 24.11 & 240 & 5786 & 5.786 \\
\hline 3. & 24.05 & 240 & 5772 & 5.772 \\
\hline 4. & 22.93 & 240 & 5503 & 5.503 \\
\hline 5. & 24.32 & 240 & 5837 & 5.837 \\
\hline
\end{tabular}

Table 6

Table 7 Some of the values obtained from the AC measurement (Phase B) in BEN198 is as follows

\begin{tabular}{|c|c|c|c|c|}
\hline S/N & Current (I) & Voltage (V) & Power (W) & Power (KW) \\
\hline 1. & 18.32 & 240 & 4397 & 4.397 \\
\hline 2. & 19.11 & 240 & 4586 & 4.586 \\
\hline 3. & 19.43 & 240 & 4663 & 4.663 \\
\hline 4. & 18.89 & 240 & 4534 & 4.534 \\
\hline 5. & 18.83 & 240 & 4519 & 4.519 \\
\hline
\end{tabular}

Table 7

Table 8 Some of the values obtained from the AC measurement (Phase C) in BEN198 is as follows

\begin{tabular}{|c|c|c|c|c|}
\hline S/N & Current (I) & Voltage (V) & Power (W) & Power (KW) \\
\hline 1. & 18.3 & 240 & 4392 & 4.392 \\
\hline 2. & 18.77 & 240 & 4505 & 4.505 \\
\hline 3. & 20.17 & 240 & 4841 & 4.841 \\
\hline 4. & 18.05 & 240 & 4332 & 4.332 \\
\hline 5. & 18.42 & 240 & 4421 & 4.421 \\
\hline
\end{tabular}

Table 8

These values in table 3-8, other subsequent values that did not appear in tables were used to obtain $3 \mathrm{G}$ plots for AC power consumption in BEN035 and BEN198 respectively.

The changes in the alternating current (AC) power consumption of the entire base station site for phase $\mathrm{A}, \mathrm{B}$ and $\mathrm{C}$ of the three phase electric supply are shown in figures $4-9$, respectively.

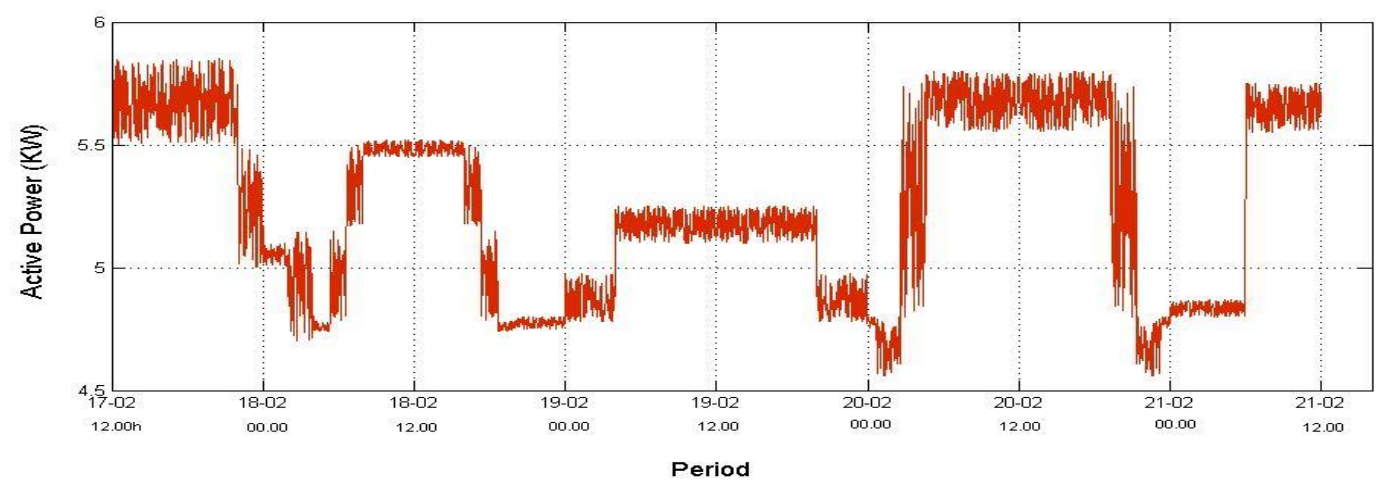

Fig 4:- Active power of phase A for 17-21 February (BEN035). 


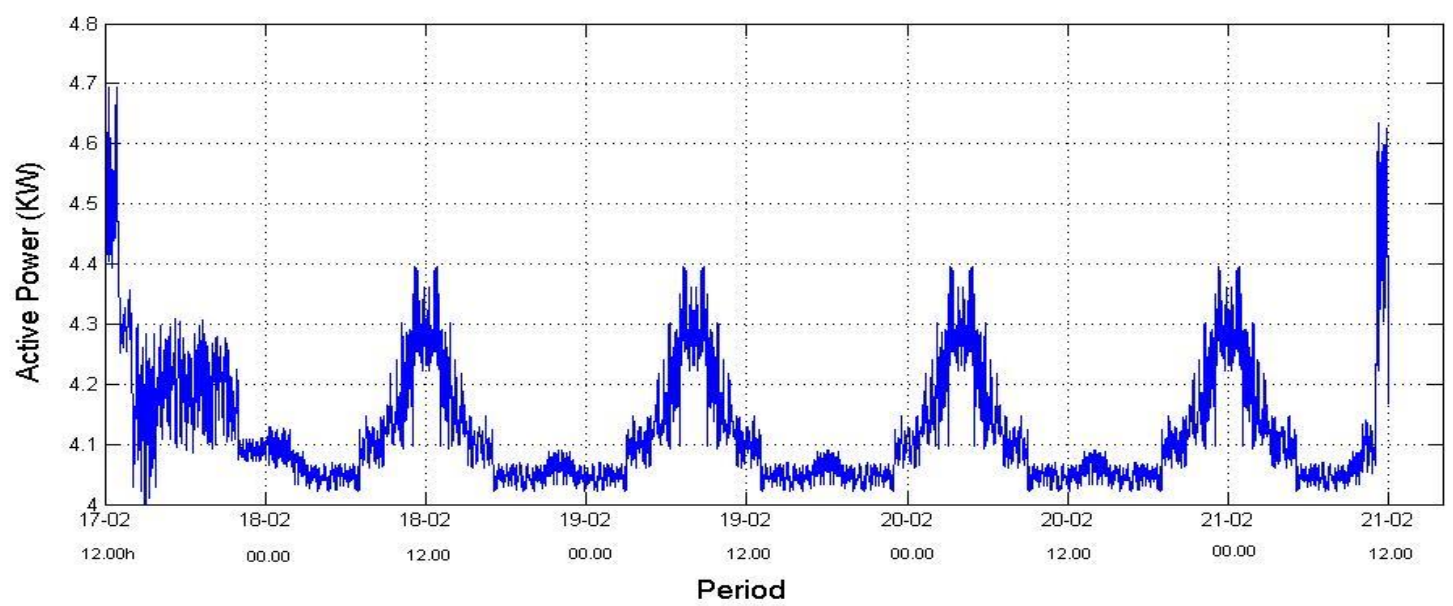

Fig 5:- Active power of phase B for 17-21 February (BEN035).

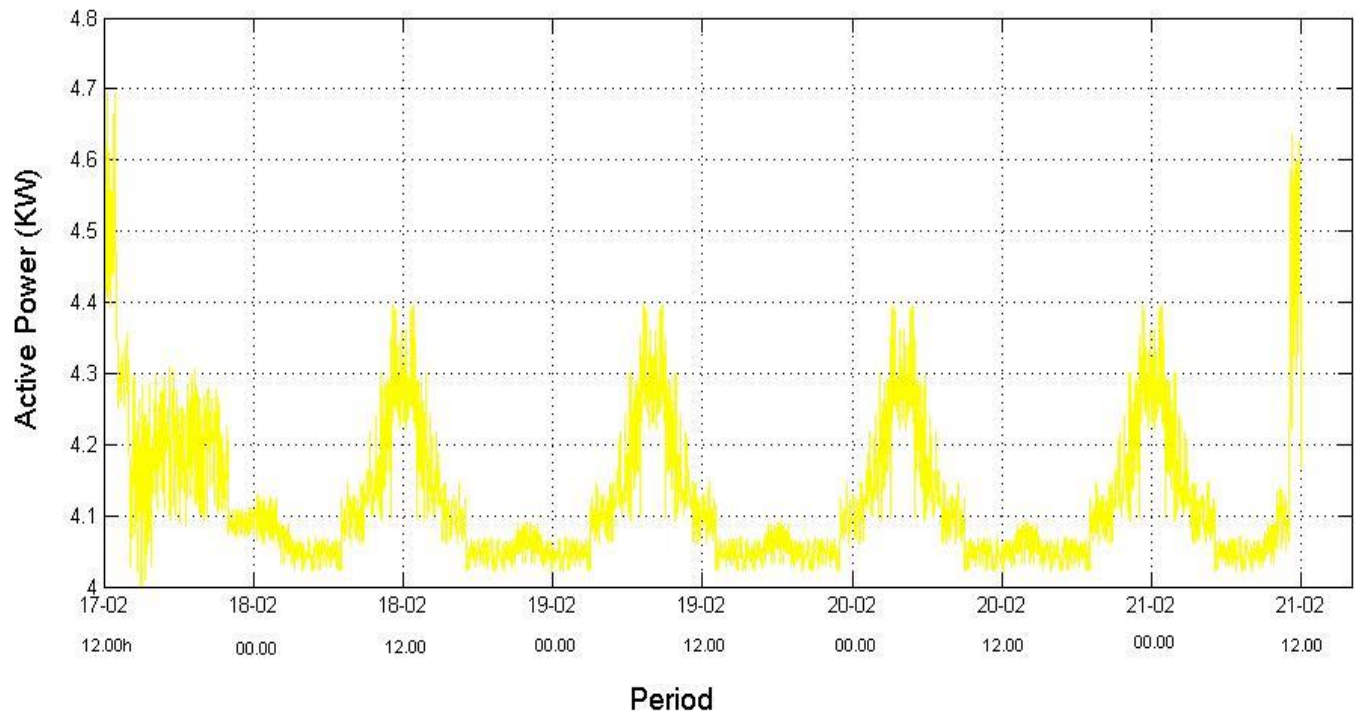

Fig 6:- Active power of phase C for 17-21 February (BEN035).

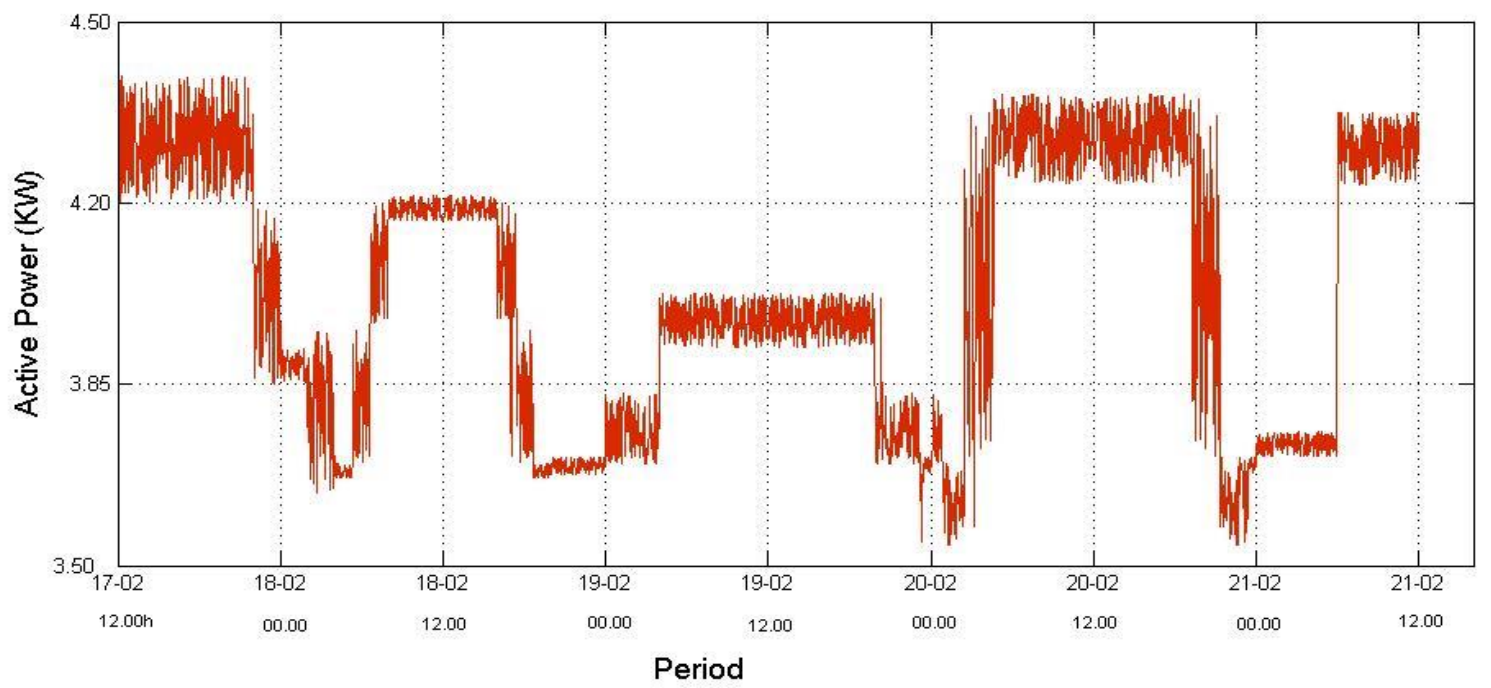

Fig 7:- Active power of phase A for 17-21 February (BEN198). 


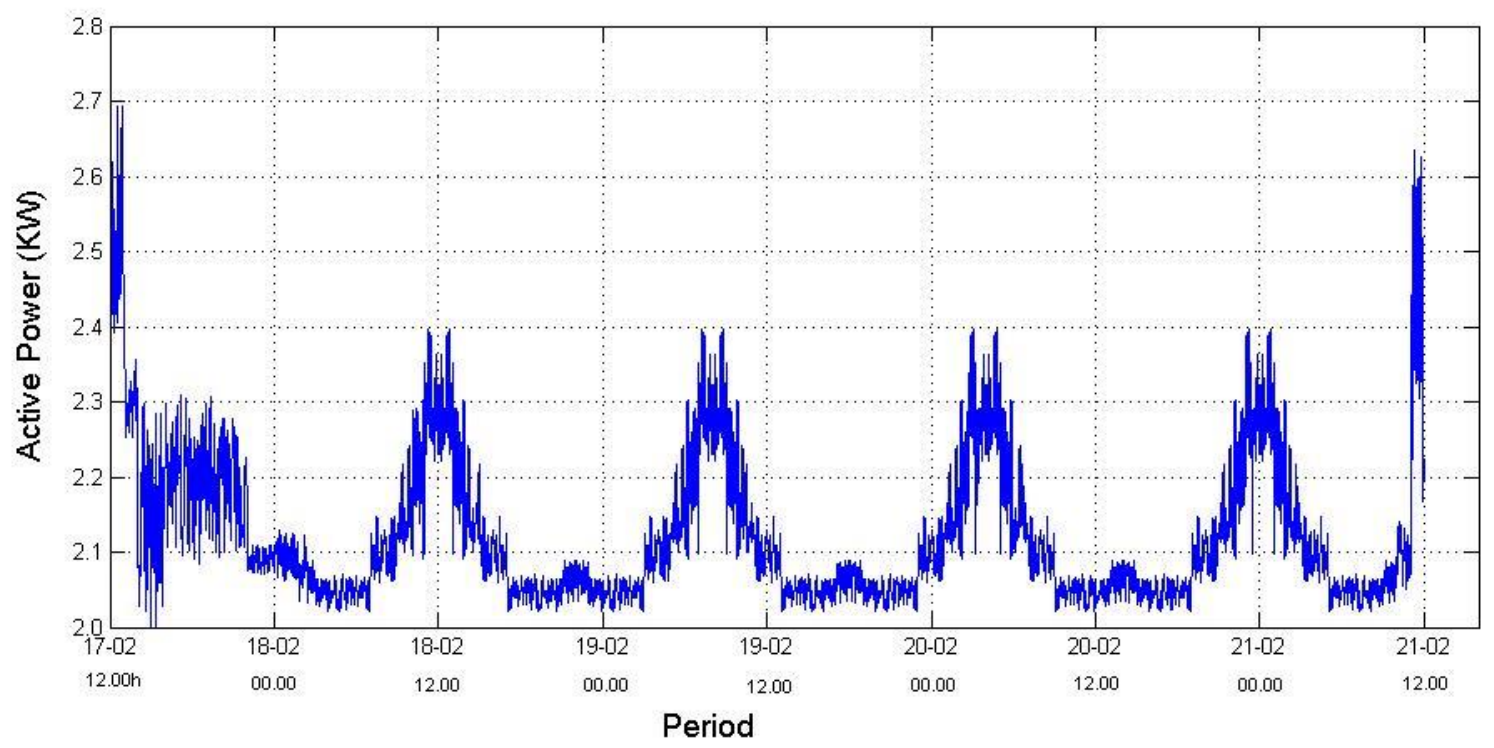

Fig 8:- Active power of phase B for 17-21 February (BEN198).

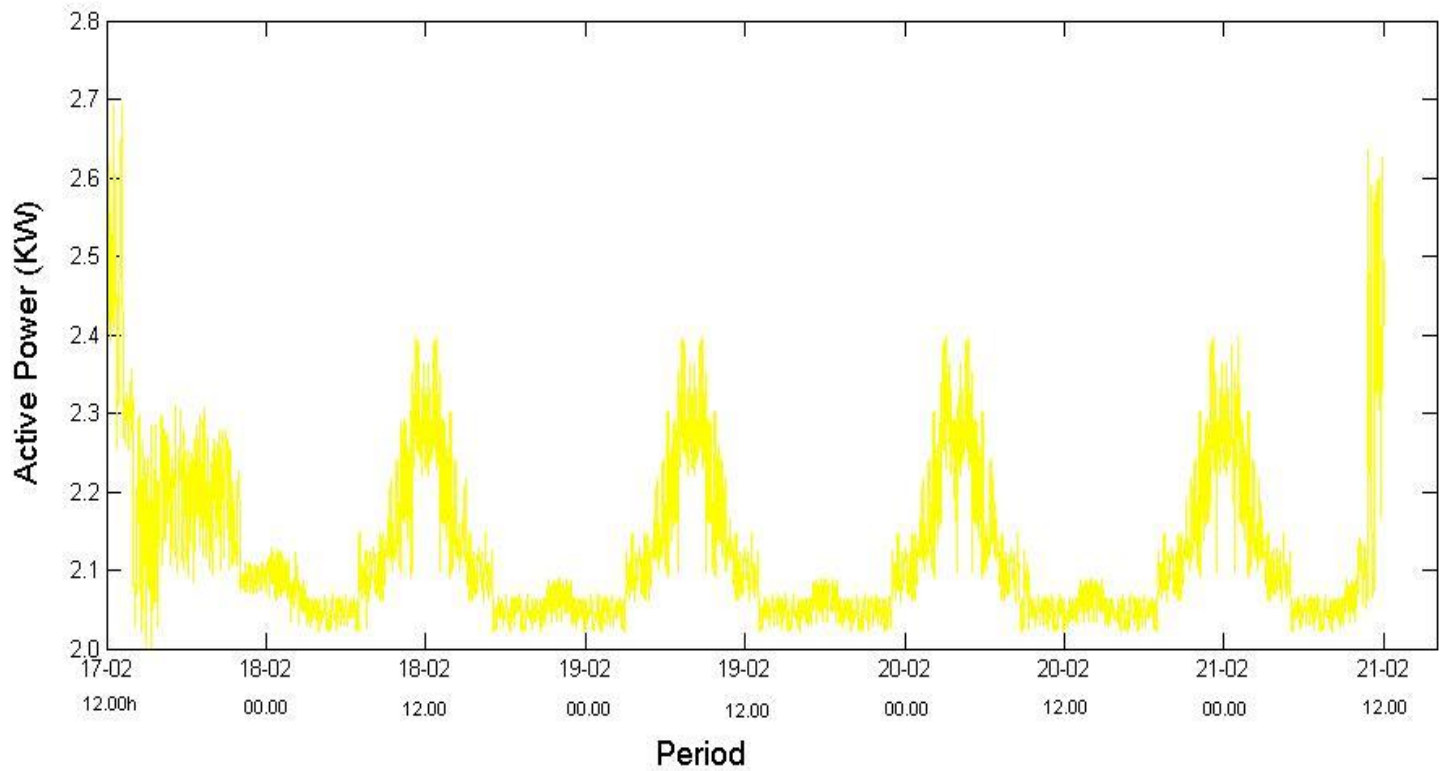

Fig 9:- Active power of phase C for 17-21 February (BEN198).

As a direct consequence, we noticed that there is more visible variations in phase $A$, which is as a result of the air conditioning connected to that phase. Therefore, reduction in the energy consumption of the individual base station sites a huge contribution to the energy contribution reduction of the complete macro base station site on the alternating current (AC) side. Also, reduced energy consumption of base stations will result in weakened heat dissipation, which consequently results in in lower energy consumed for site cooling. The appropriate design of macro base station sites, especially in the case of outdoor base station sites with natural air-cooling base station racks, can be used in order to completely eliminate the need for electrically supplied air-conditioning.

\section{INSTANTANEOUS DC POWER CONSUMPTION}

In this research, consideration was taken for two universal mobile telecommunication system (UMTS) 3G BS cabinets dedicated for transferring traffic.

Changes in the instantaneous power consumption of the $3 \mathrm{G} \mathrm{BS}$ is presented in Figure 10 for BEN035 and $3 \mathrm{G}$ $\mathrm{BS}$ is presented in Figure 11 for BEN198. These power consumptions of the individual Base stations were obtained by multiplying the measured values of the instantaneous Base station electric current consumption with constant DC voltage $(53.6 \mathrm{~V})$. According to Figures 10 and 11, it was observed that the power consumption of each Base station is not constant at every given time. 
The first five values of current from the 2880 values obtained in the period were shown in the tables below.

Table 9 Some of the values obtained from the DC power consumption in BEN035 is as follows

\begin{tabular}{|c|c|c|c|c|}
\hline S/N & Current $(\mathrm{I})$ & Voltage $(\mathrm{V})$ & Power $(\mathrm{W})$ & Power $(\mathrm{KW})$ \\
\hline 1. & 11.3 & 53.6 & 603 & 0.603 \\
\hline 2. & 12.6 & 53.6 & 675 & 0.675 \\
\hline 3. & 11.9 & 53.6 & 638 & 0.638 \\
\hline 4. & 11.8 & 53.6 & 634 & 0.634 \\
\hline 5. & 12.8 & 53.6 & 688 & 0.688 \\
\hline
\end{tabular}

Table 9

Table 10 Some of the values obtained from the DC power consumption in BEN198 is as follows

\begin{tabular}{|c|c|c|c|c|}
\hline S/N & Current (I) & Voltage (V) & Power (W) & Power (KW) \\
\hline 1. & 10.0 & 53.6 & 537 & 0.537 \\
\hline 2. & 10.6 & 53.6 & 567 & 0.567 \\
\hline 3. & 8.5 & 53.6 & 454 & 0.454 \\
\hline 4. & 9 & 53.6 & 480 & 0.481 \\
\hline 5. & 12.8 & 53.6 & 509 & 0.509 \\
\hline
\end{tabular}

Table 10

These values in table 9 and 10, other subsequent values that did not appear in tables were used to obtain $3 \mathrm{G}$ plots for DC power consumption in BEN035 and BEN198 respectively.

Actually, the instantaneous power consumption of the BSs varies during a day and these variations are inherent for the analyzed mobile technology (3G BTS).

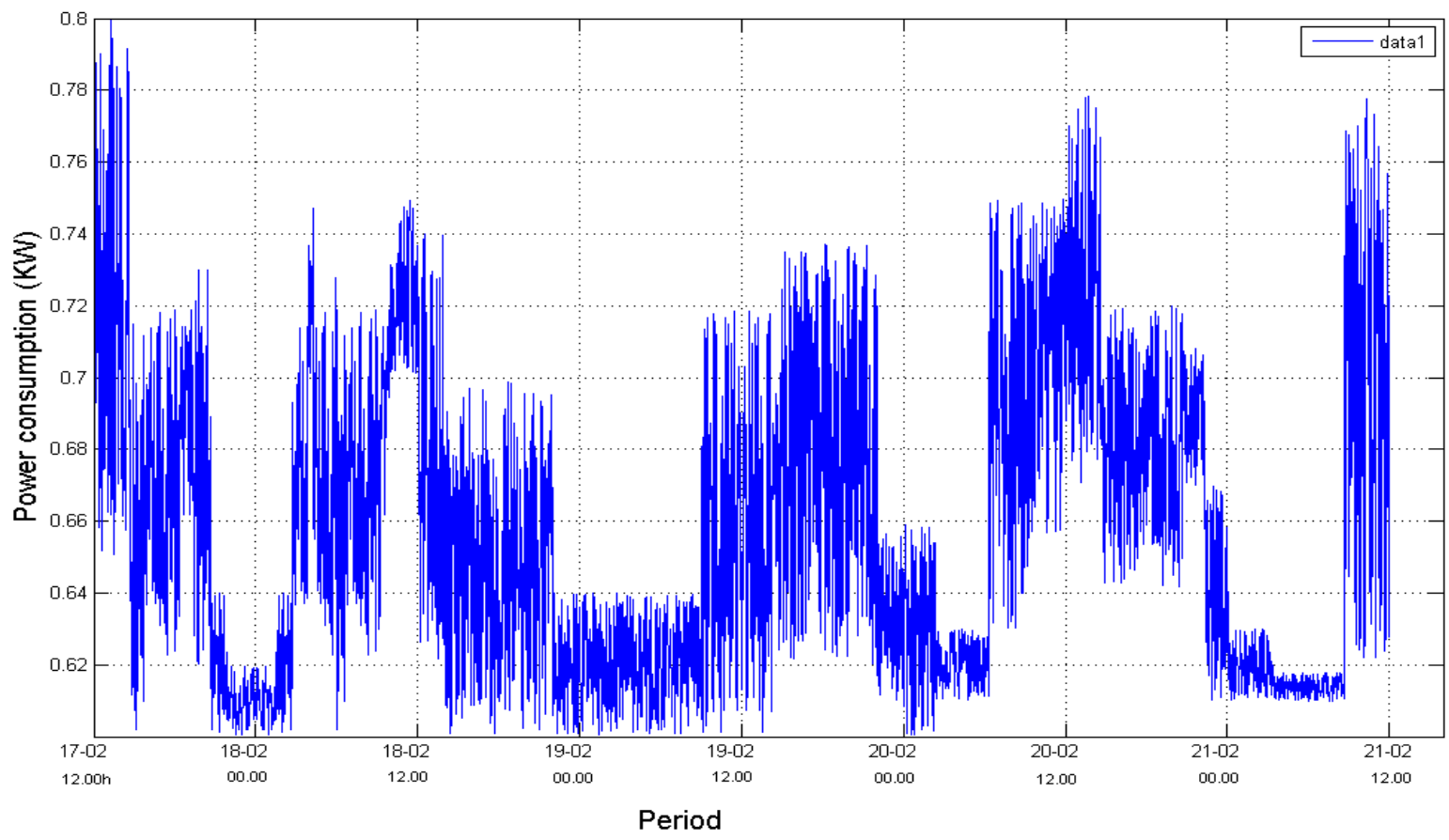

Fig 10:- Power consumption of 3G (Sector 1) BS cabinet (BEN035). 


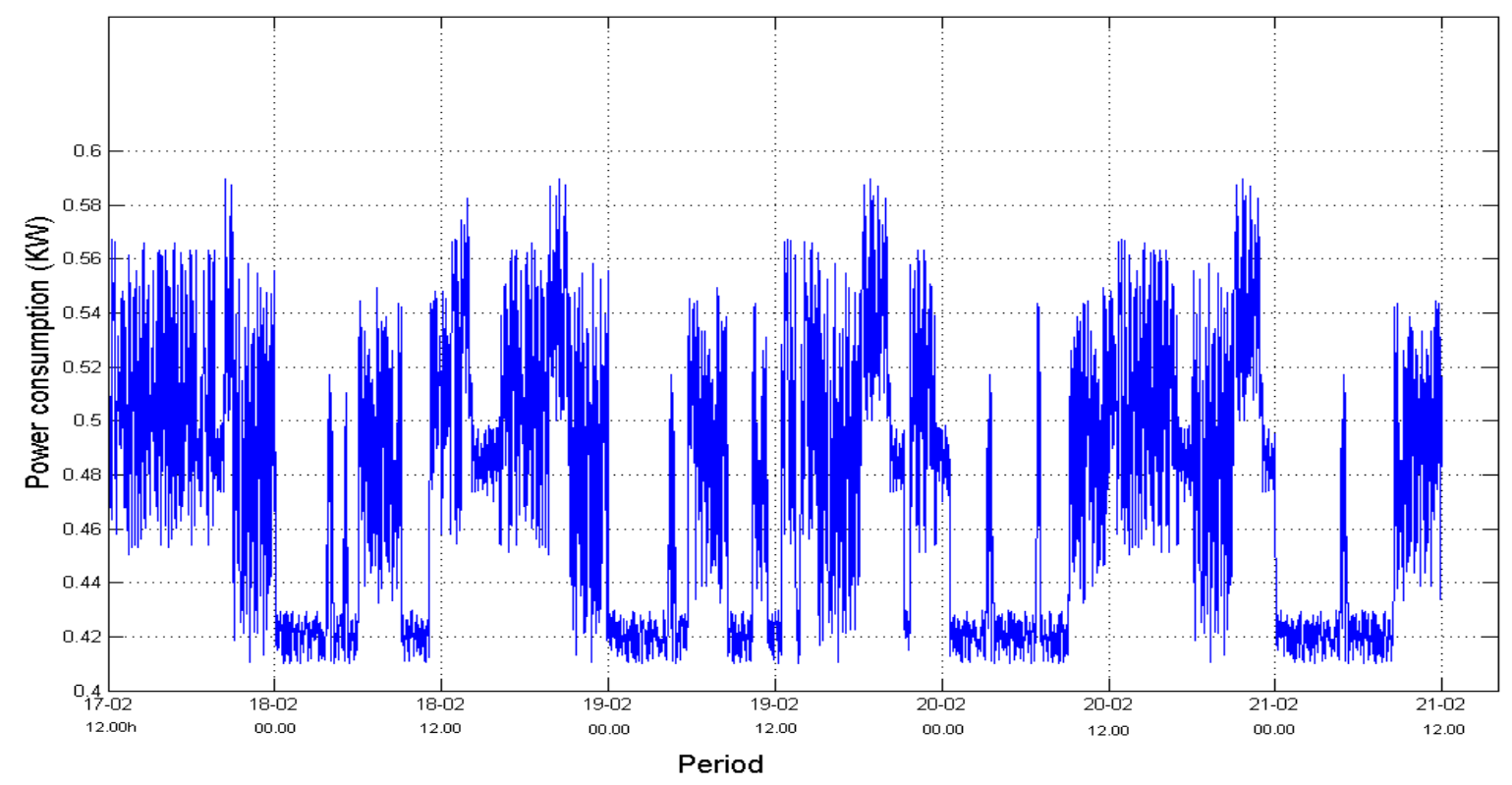

Fig 11:- Power consumption of 3G (Sector 1) BS cabinet (BEN198).

From figure 10 and 11 it is observed that the highest power consumer is the $3 \mathrm{G}$ BS cabinet of BEN035, Compared with the base station consumption of the $3 \mathrm{G}$ BS cabinet of BEN198. This 3G BS of BEN035 has higher instantaneous power consumption at any moment. This is because the 3G BS of BEN035 cabinet serves all four sectors concurrently through configuration with 4 transceivers (TRXs) per sector (1/1/1/1). Since each transceiver has a separate power amplifier, and the power amplifier has the major share in the BS power consumption, the number of transceivers has an important influence on the total Base station power consumption. With this, the influence on the power consumption will be somewhat determined by the fact that the $3 \mathrm{G}$ Base station of BEN035 has been selected for maximum capacity utilization.

When power consumption was reduced by reducing the power consumed by some of the equipment that make up the BTS by using a lower power rated transceiver, multiplexer and base band unit, the plot remained exactly the same but spanned from $6 \mathrm{kw}$ to $4 \mathrm{kw}$ in $3 \mathrm{G}$ BS for BEN035, and from $4 \mathrm{kw}$ to $2 \mathrm{kw}$ in $3 \mathrm{G}$ BS for BEN198. This was carried out in the period from $24^{\text {th }}$ February starting at $12: 00 \mathrm{pm}$ until $28^{\text {th }}$ February ending at $12: 00 \mathrm{pm}$. It is presented from Figure 12 and 13.

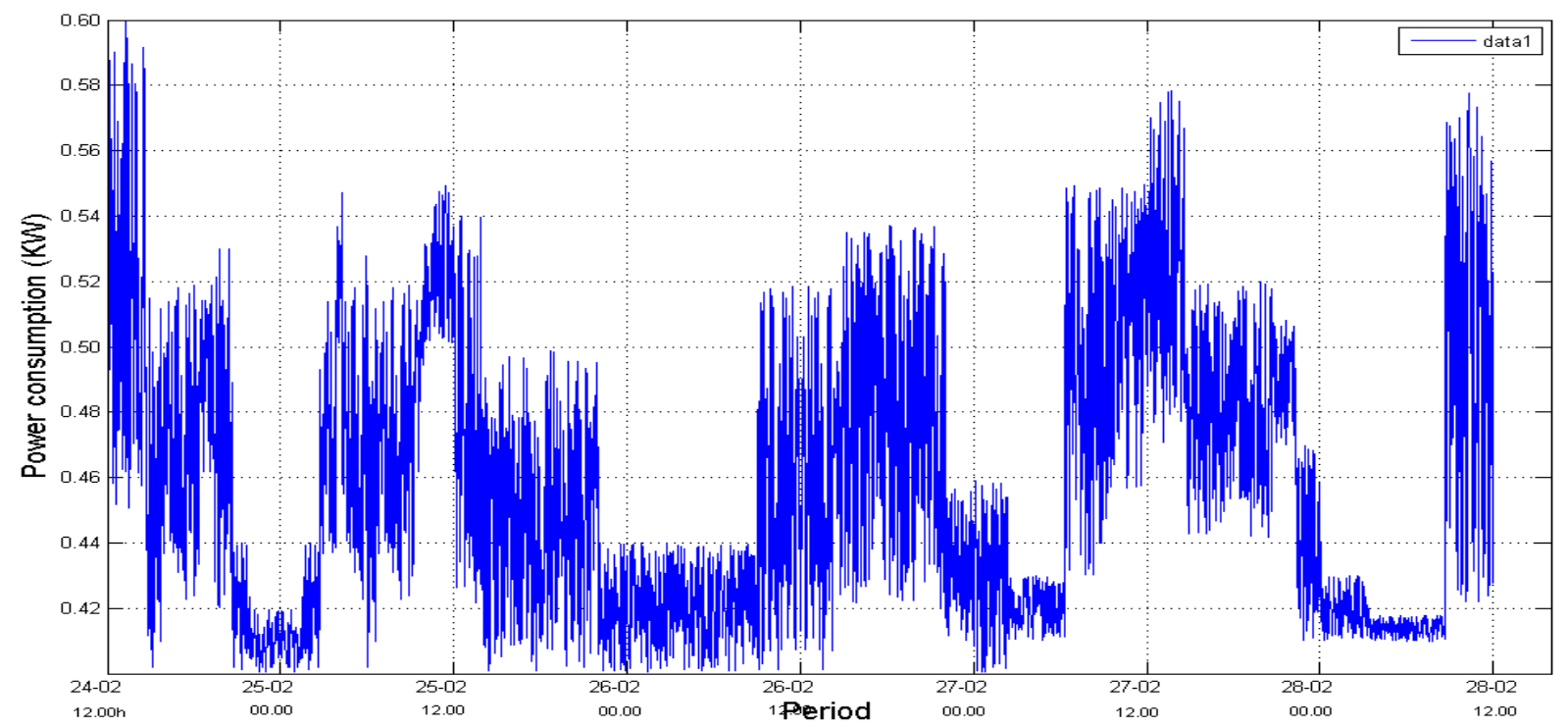

Fig 12:- Power consumption (Low) of 3G (Sector 1) BS cabinet (BEN035). 


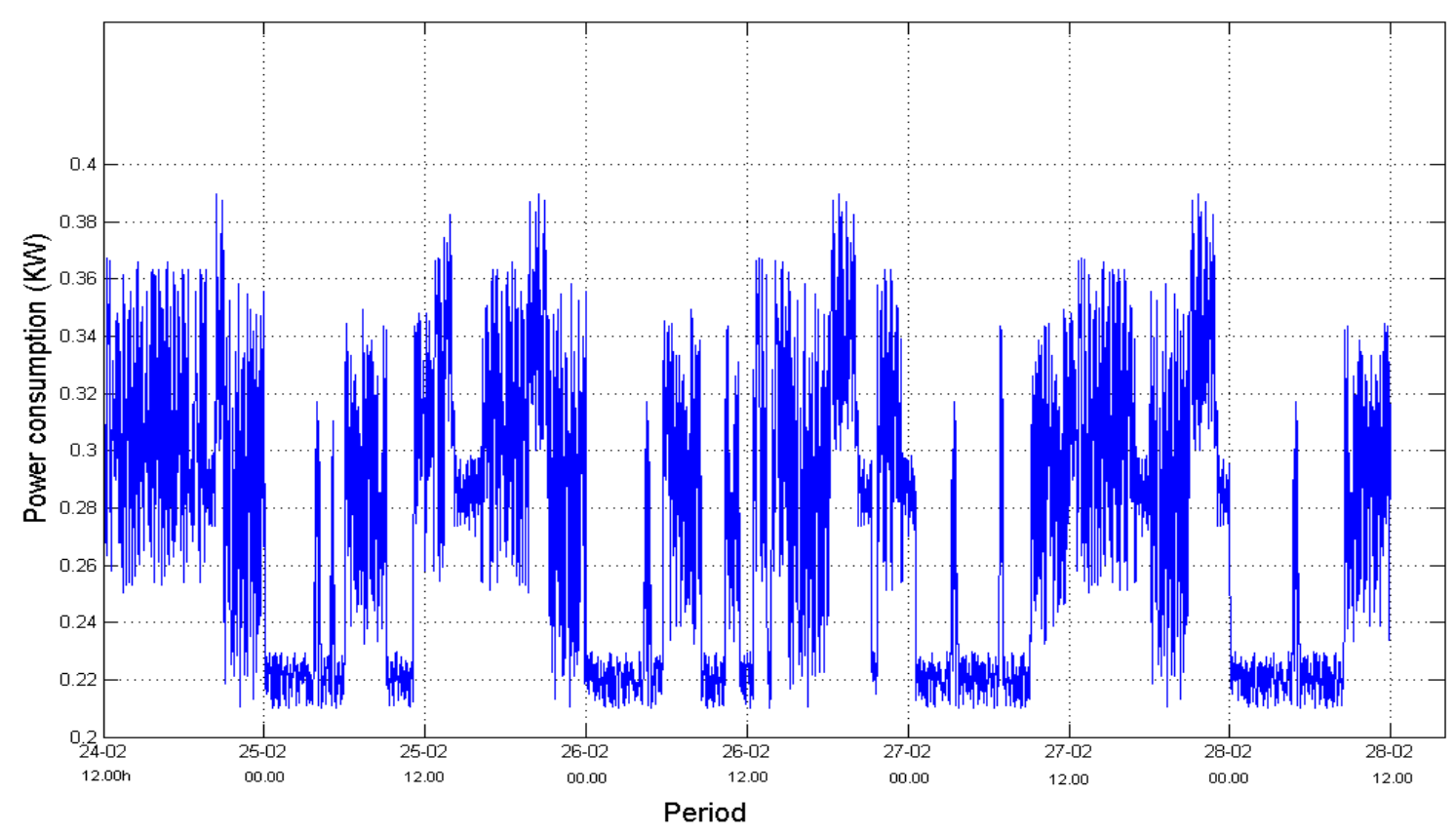

Fig 13:- Power consumption (Low) of 3G (Sector 1) BS cabinet (BEN198).

\section{POWER CONSUMPTION MODELLING}

Depending on the measured average traffic load and the instantaneous power consumption obtained for each base station rack on the direct current (DC) side, the essence is to produce a linear base station power consumption model. The developed model must express instantaneous power consumption of each BS rack as a function of the current traffic load. In order to model the interdependence between the power consumption of each BS rack and corresponding traffic load, we use the following equation:

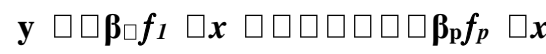

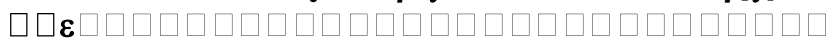

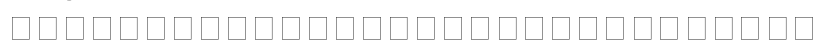

According to Equation (1), response $y$ is modelled as a linear combination of functions of independent variable $x$ and a random error $\varepsilon$. In expression $(1), f j(\boldsymbol{x})(j=1, \ldots, p)$ are the terms of the model, while $\beta j(j=1, \ldots, p)$ represents the coefficients. It is assumed that the model has up to $p$ different terms and corresponding coefficients. Uncontrolled factors and experimental errors are modelled in Equation (1) by $\varepsilon$, and assumed to be uncorrelated and distributed with zero mean and constant variance.

In our linear model, terms are $f 1(x)=1$ and $f 2(x)=x$. For $n$ independent observations $(x 1, y 1), \ldots,(x n, y n)$, the linear regression model becomes an $n \times 2$ system of equations:

$$
\left[\begin{array}{c}
y_{1} \\
y_{2} \\
\vdots \\
y_{n}
\end{array}\right]=\left[\begin{array}{cc}
f_{1} x & f_{2} x \\
f_{1} x & f_{2} x \\
\vdots & \vdots \\
f_{1} x & f_{2} x
\end{array}\right]\left[\begin{array}{c}
\beta_{1} \\
\beta_{2}
\end{array}\right]+\left[\begin{array}{c}
x_{1} \\
x_{2} \\
\vdots \\
x_{n}
\end{array}\right]
$$

or, in the matrix notation:

$$
\mathbf{y} \square \square \mathbf{X} \boldsymbol{\beta} \square \square \boldsymbol{\varepsilon}
$$

The $\mathbf{X}$ in Equation (3) is the design matrix of the system (Jacobiana). To fit the model with the data, the system must be solved for the coefficient $\beta 1$ and $\beta 2$.

Ignoring the unknown errors $\boldsymbol{\varepsilon}$, the matrix equation expressed in Equation (3) can be written and solved as follows:

$$
\begin{aligned}
& \mathbf{y} \square \square \mathbf{X} \boldsymbol{\beta} \\
& \mathbf{X}^{\mathrm{T}} \mathbf{y} \square \mathbf{X}^{\mathrm{T}} \mathbf{X} \boldsymbol{\beta} \\
& \boldsymbol{\beta} \square \square \square\left(\mathbf{X}^{\mathbf{T}} \mathbf{X}^{-1}\right) \mathbf{X}^{T} \mathbf{y}
\end{aligned}
$$

For calculation of a confidence region, we need a variance $s$ of coefficients $\beta 1$ and $\beta 2$. The approximate variance-covariance matrix of the regression coefficients is estimated by:

$$
S^{2}(\boldsymbol{\beta})=\frac{\mathbf{x x}^{T}}{n-2}\left(\mathbf{X}^{T} \mathbf{X}\right)^{-1}
$$

\section{A. Telecommunication Traffic}

Mobile telephone traffic data can be used to characterize resource usage and subscriber behaviors in mobile networks. Telecommunication traffic is measured in erlang. 


\section{B. ERLANG}

An erlang is a unit of telecommunication traffic measurement. It represents the continuous use of one voice path. In practice, it is used to describe the total traffic volume of one hour.

For example, if a group of user made 30 calls in one hour, and each call had average call duration of 5 minutes, then the number of erlang this represents is worked out as follows:

Minutes of traffic in the hour $=$ number of calls $\mathrm{x}$ duration

Minutes of traffic in the hour $=30 \times 5$

Minutes of traffic in the hour $=150$

Hours of traffic in the hour $=150 / 60$

Hours of traffic in the hour $=2.5$

Traffic figure $=2.5$ Erlangs

Erlang traffic measurements are made in order to help telecommunication network designers understand traffic patterns within their voice networks. Traffic performance parameters are used to estimate the capacity and system utilization rate. This is essential if they are to successfully design their network topology and establish the necessary trunk group sizes.

The data/call traffic, which is a key performance indicator was collated by the radio network controller (RNC) for 3G and extracted through the operations and maintenance centre (OMC).

For a given period, from February $17^{\text {th }}$ at $12: 00 \mathrm{pm}$ to February $21^{\text {st }}$ at $12: 00 \mathrm{pm}$, let the telecommunication traffic $\operatorname{Tr}(\mathrm{Erl})$ be represented as independent variable $\mathrm{x}$, while the measured power $(\mathrm{P})$ be represented as response $\mathrm{y}$. Then the coefficient of regression line are: $\beta 1$ [W], which represents the intercept, and $\beta 2[\mathrm{~W} / \mathrm{Erl}]$ which represents the slope of the line. Calculations were done by the use of function regression that is incorporated in a matlab software package. For the purpose of this work, power consumption measurements were taken at 60 values interval to obtain a better range of values for the model. The obtained results are shown in table 11 and the model in Figures 14 and 15.

Table 11 Average Power and Traffic for BEN035 and BEN198

\begin{tabular}{|c|c|c|c|c|}
\hline$(\mathrm{S} / \mathrm{N})$ & $\begin{array}{l}\text { Average Power P (W) for } \\
\text { BEN035 }\end{array}$ & $\begin{array}{l}\text { Average Traffic Tr (Erl) for } \\
\text { BEN035 }\end{array}$ & $\begin{array}{l}\text { Average Power P }(\mathrm{W}) \text { for } \\
\text { BEN198 }\end{array}$ & $\begin{array}{l}\text { Average Traffic Tr (Erl) } \\
\text { for BEN198 }\end{array}$ \\
\hline 1. & 640 & 2 & 420 & 2 \\
\hline 2. & 635 & 2 & 423 & 2.1 \\
\hline 3. & 640 & 3 & 425 & 3.2 \\
\hline 4. & 650 & 4 & 435 & 4 \\
\hline 5. & 645 & 5.2 & 440 & 5 \\
\hline 6. & 650 & 4.3 & 445 & 4 \\
\hline 7. & 660 & 5 & 450 & 5 \\
\hline 8. & 653 & 5 & 455 & 5.2 \\
\hline 9. & 644 & 6 & 457 & 6 \\
\hline 10. & 660 & 6.2 & 462 & 6 \\
\hline 11. & 670 & 6 & 465 & 6 \\
\hline 12. & 680 & 6.5 & 460 & 6.3 \\
\hline 13. & 690 & 5.5 & 462 & 5.4 \\
\hline 14. & 680 & 8 & 470 & 8.5 \\
\hline 15. & 700 & 8 & 470 & 8 \\
\hline 16. & 680 & 8 & 473 & 8 \\
\hline 17. & 680 & 8 & 480 & 8.2 \\
\hline 18. & 715 & 8 & 477 & 8 \\
\hline 19. & 725 & 8 & 485 & 8 \\
\hline 20. & 720 & 9 & 489 & 9 \\
\hline 21. & 724 & 10 & 490 & 10.1 \\
\hline 22. & 730 & 11 & 500 & 11 \\
\hline 23. & 735 & 11 & 520 & 11.1 \\
\hline 24. & 740 & 12 & 510 & 12 \\
\hline 25. & 710 & 12 & 515 & 12 \\
\hline 26. & 748 & 12 & 520 & 12.3 \\
\hline 27. & 750 & 13 & 523 & 13 \\
\hline 28. & 752 & 13 & 530 & 13 \\
\hline 29. & 749 & 13 & 535 & 13 \\
\hline 30. & 755 & 14 & 540 & 14.2 \\
\hline 31. & 760 & 14 & 537 & 14 \\
\hline 32. & 758 & 15 & 545 & 15 \\
\hline
\end{tabular}


ISSN No:-2456-2165

\begin{tabular}{|c|c|c|c|c|}
\hline 33. & 742 & 16 & 550 & 16 \\
\hline 34. & 759 & 16 & 552 & 16.5 \\
\hline 35. & 765 & 16 & 554 & 16 \\
\hline 36. & 770 & 17.3 & 560 & 17 \\
\hline 37. & 763 & 17.1 & 563 & 17 \\
\hline 38. & 769 & 17 & 567 & 17.5 \\
\hline 39. & 775 & 17.5 & 566 & 18 \\
\hline 40. & 780 & 18 & 570 & 18.5 \\
\hline 41. & 782 & 18 & 575 & 18.5 \\
\hline 42. & 784 & 18.5 & 571 & 18.1 \\
\hline 43. & 783 & 18.5 & 578 & 18 \\
\hline 44. & 790 & 18.5 & 580 & 19 \\
\hline 45. & 787 & 18 & 584 & 19 \\
\hline 46. & 781 & 18.8 & 590 & 20 \\
\hline 47. & 792 & 19.2 & 595 & \\
\hline 48. & 795 & 20 & 597 & \\
\hline
\end{tabular}

Table 11

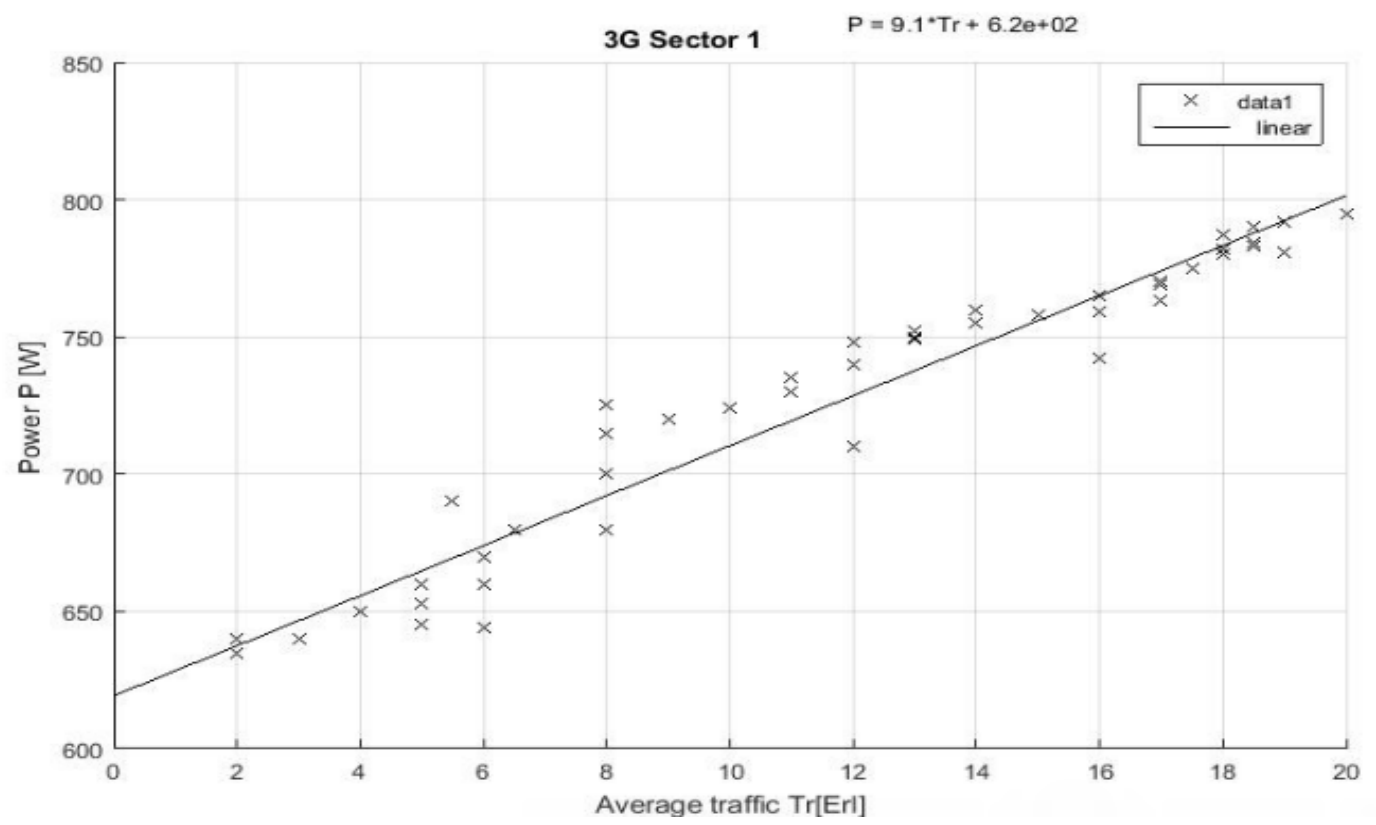

Fig 14:- Power consumption model of 3G sector 1 BS rack (total measuring period) for BEN035.

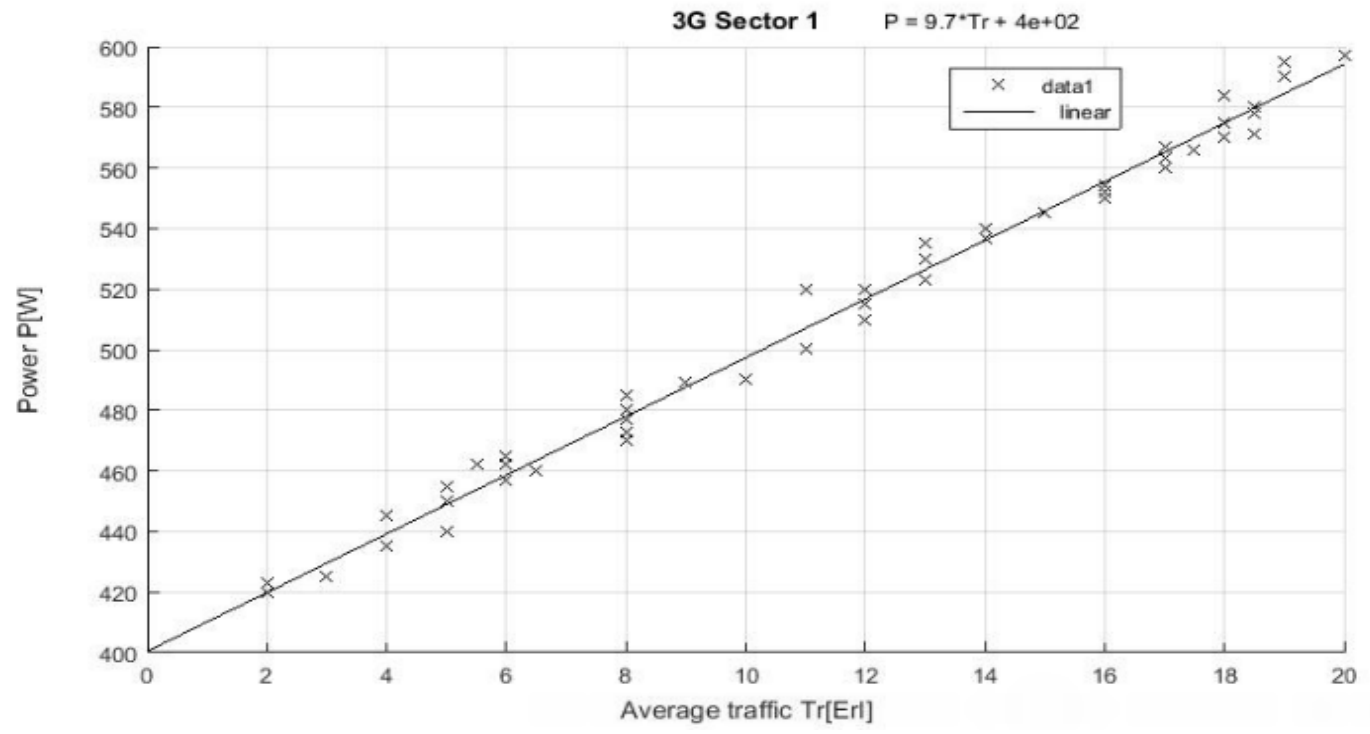

Fig 15:- Power consumption model of 3G sector 1 BS rack (total measuring period) for BEN198. 


\section{Model Analysis and Results}

From the equations of the model as shown in fig 14 and 15 , this is the same as the equation of a straight line, $\mathrm{Y}=\mathrm{mx}+\mathrm{c}$

$\mathrm{Y}$ is the dependent variable, $\mathrm{m}$ is the gradient, $\mathrm{x}$ is the independent variable, predictor or regressor and $\mathrm{c}$ is the intercept.

For base station A (BEN035), we have the model equation to be:

$\mathrm{P}=9.1 * \mathrm{Tr}+6.2 \mathrm{e}+02$

Where $\mathrm{P}$ is the dependent variable, 9.1 is the gradient, $\mathrm{Tr}$ is the average traffic and $6.2 \mathrm{e}+02$ is the intercept (euler constant).

For base station B (BEN198), we have the model equation to be:

$\mathrm{P}=9.7 * \mathrm{Tr}+4 \mathrm{e}+02$

Where $\mathrm{P}$ is the dependent variable, 9.7 is the gradient, $\operatorname{Tr}$ is the average traffic and $4 \mathrm{e}+02$ is the intercept (euler constant)

The model equations $\mathrm{P}=9.1 * \mathrm{Tr}+6.2 \mathrm{e}+02$ for BEN035 and $\mathrm{P}=9.7 * \mathrm{Tr}+4 \mathrm{e}+02$ for BEN198 are used to determine the unit change of independent variable (Average traffic) on the dependent variable (Power) for the system

From the model equations of the two base stations under consideration, comparism can be made on the base transceiver station that consumes more power and lesser power. It is evident that base station A (BEN035) consumes more power than base station B (BEN198). This shows that there are more network subscribers on base station $\mathrm{A}$ compared to base station B.

In Figures 14 and 15, in figures 14 and 15, 95\% confidence interval was obtained from the developed linear models which have been plotted together with the measured results and the linear regression lines. According to these figures, it was possible to model the linear dependence of the instantaneous power consumption on the traffic load. An increase in the traffic load results in a linear increase of the instantaneous base station power consumption and also, the linear increase of the instantaneous base station power consumption results in an increase in the traffic load. In most cases, even when the traffic load is very low, the proposed model will still ensure some fixed amount of power consumption. The proposed linear model is made up of two components, which is fixed (not dependent on traffic load) and variable (directly proportional to traffic load). Each of the linear model obtained corresponds to the particular base station technology of the different sites and base stations of different manufacturers, year of production might have different linear models. Since the significant percentage of confidence is in line with the results gotten from the site measurements, the linear power consumption model can be seen as a model for evaluating the interdependence between traffic load and instantaneous base station power consumption. This perception gives as much possible confidence to the usage of a linear model in future studies which is focused on enhancing the energy efficiency of mobile radio access equipment already installed.

This model will help telecommunication network designers and operators understand traffic patterns and the power consumption in a base station. Decisions can then be taken to increase the number of base transceiver stations or increase the capacity of the equipment to service such areas when there are large number of network subscribers.

\section{CONCLUSION}

In this research, overview of the latest activities focused on enhancing the power consumption efficiency of base stations and low cost of operation. Additionally, an investigation regarding the impact of the power consumed by equipment that makes up the Base stations was performed. Analyses have been performed on the BS equipment containing rectifier, transceiver, air condition, baseband unit, amplifier, microwave link and antenna. Power consumption model for each analysed base station sites was produced. From the site measurements, a significant percentage of confidence follows the result from the proposed model. Therefore, the linear power consumption model can be seen as a model for evaluating the interdependence between traffic load and instantaneous base station power consumption.

\section{REFERENCES}

[1]. Faruk N., Ayeni A. A. and Mohammad M. Y., (2013) Techniques for minimizing power consumption of base transceiver station in mobile cellular systems, International Journal of Sustainability, Volume 2(1). Pp 2-6.

[2]. Josip L., Tonko G. and Goran P., (2012), Measurement and modelling of base station power consumption under real time traffic loads. Pp 4282.

[3]. Margot D., Wout J. and Luc M. (2011), Power consumption for macro and micro base station, $\mathrm{Pp} 2$.

[4]. Osahenvemwen O. A. and Emagbetere J., (2012) Determination of traffic load and traffic performance parameters in mobile communication in Nigeria, Research Journal of Applied Sciences, Engineering and Technology Vol 4(11), Pp 1435.

[5]. Payel G. and Sudhansu S. (2015), An analytical survey of power consumption and modelling in different areas of ICT networks, International Journal of Computer Science and Information Technologies, Vol. 6(1), Pp 867.

[6]. Sihai Z., Dandan Y., Vanqin Z. and Wuyang Z., (2015) Computation on base station behavior using erlang measurement and call detail record, Jan, Vol 3(3), Pp 446.

[7]. Antonio S., Petraglia A, Carmela V., Roberto F. and Carmine L., (2015), Monitoring and optimization of energy consumption of base transceiver stations, Pp 1 . 